\title{
Zoonotic Potential of Rotavirus from Swine and Bovine in South of Taiwan
}

\author{
Dewi Murni ${ }^{1,2^{*}}$, Pratiwi Trisunuwati ${ }^{2}$, Ming Hui Liao ${ }^{3}$ \\ ${ }^{1}$ Department of Veterinary Medicine, National Pingtung University of Science and Technology, Pingtung, Taiwan \\ ${ }^{2}$ Department of Animal Husbandry, University of Brawijaya, Malang, Indonesia \\ ${ }^{3}$ Department of Veteinary Medicine, National Pingtung University of Science and Technology, Pingtung, Taiwan
}

\begin{abstract}
Rotavirus was recognized as the virus that responsible for causing acute gastroenteritis, especially young livestock. Taiwan Center for Disease Control (CDC) confirms the majority cases of acute gastroenteritis in Taiwan on February 2015 were caused by rotavirus. In this study, we report the incidence and zoonotic impact of rotavirus strain from Taiwan. This study examined 90 (swine) and 60 (bovine) fecal samples collected from south of Taiwan in March 2015. Detection of rotavirus using VP6 gene by RT-PCR technique with amplicons $379 \mathrm{bp}$. Zoonotic potential analysis based on nucleotide sequence and phylogenetic analysis. RT-PCR utilizing the primers specific for VP6 gene detected rotavirus with positive reactions $3 / 30(10 \%)$ in piglets and $1 / 20(5 \%)$ in the calf. Based on the nucleotide sequences and phylogenetic analysis indicated that 1 of 3 wild strains from swine rotavirus had $85.0 \%-91.1 \%$ and 1 wild strain from bovine had $78.7 \%-85.9 \%$ identity relations with human strains. These findings indicated that the wild strains of swine and bovine rotavirus may broadly spread and contribute to zoonotic transmission.
\end{abstract}

Keywords: Bovine, Rotavirus, RT-PCR, Swine, Zoonotic.

\section{INTRODUCTION}

Rotavirus is enteric pathogen causing acute watery diarrhea in young man and various animal species. About two million hospitalizations and 453.000 deaths in young children below 5 years of age every year [1,2]. Rotavirus is belongs to family reoviridae, icosahedral in structure, 60-80 $\mathrm{nm}$ in diameter, non enveloped, possess a one, two or three layered capsid, and containing a genome of 11 segements of double stranded RNA (dsRNA) encoding six structural (VP1, VP2, VP3, VP4, VP6, and VP7) and five or six nonstructural (NSP 1-6) proteins [3]. This virus can be transmitted by consuming contaminated food and direct contact with an infected individual or contaminated objects. The symptoms include diarrhea, nausea, vomiting, some stomach cramping, and sometimes people have a low grade fever, headache, muscle aches, and tiredness [4].

There are eight species of rotavirus, referred to as rotavirus $A$ (the majority isolates that infect in mammalian and avian, including human), rotavirus $B$ (identified in human and rat), rotavirus $C$ (human and porcine), rotavirus D, F, and G (identified in chicken), rotavirus $E$ (porcine), rotavirus $\mathrm{H}$ (human) [5], rotavirus $\mathrm{H}$ was tentatively assigned to a novel rotavirus species [6]. Group A

\footnotetext{
* Correspondence author:

Dewi Murni

Email : dw_murni@yahoo.com

Address : Dept. of Animal Husbandry, University of Brawijaya, Jl. Veteran Malang, 65145.
}

rotavirus is recognized as the most important group that are causes highest prevalence and pathogenesis in human and animals including cattle, swine, horses, dogs, cats, chickens and turkeys $[7,8]$. Asymptomatic rotavirus infections were also known to occur in pigs in all ages [9]. VP6 is one kind of major structural protein intermediate capsid layer of rotavirus virion, VP6 plays a role as a virulence factor of the virus pathogenesis. Characterization of VP6 gene is encoded 379 amino acid sequences [10].

This study aimed to detect rotavirus from swine and bovine using molecular techniques by reverse transcriptase-polymerase chain reaction (RT-PCR) and then analyze potential zoonotic of the virus. Positive results subsequently cloned using $\mathrm{pGM}-\mathrm{T}$ vector for ligation, $\mathrm{DH} 5 \alpha$ for transformation, and sent for sequencing, the sequences data were compared with the other strains from different country or species to $\mathrm{Na}$ tional Center for Biotechnology Information (NCBI) and followed by phylogenetic analysis using Molecular Evolutionary Genetics Analysis Software (MEGA) version 6.0 and analyzed the homologous identity with multiple sequence alignments using DNASTAR software [11]. The samples were randomly collected from different pigs and cattle farms in South of Taiwan. The data were obtained on March 2015 and it can be used as a reference for control and prevention of the disease that caused by rotavirus in veterinary epidemiology. 


\section{MATERIAL AND METHODS \\ Specimen Collection}

A total of 90 fecal specimens of swine feses and 60 fecal specimens of bovine feses were used in this study. All specimens were collected by random method from different farms in south of Taiwan on March 2015. A number of 90 samples from 3 pig farms and 60 samples from 2 cattle farms were collected. Specimens were collected from 3 groups of swine (sow, fattening, and piglet) and 2 groups of cattle (cow and calf). The stool samples were frozen and stored at $20^{\circ} \mathrm{C}$ for next processing.

\section{RNA Extraction}

Viral RNA was extracted from $1 \mathrm{ml}$ PBS suspensions of stool specimens with Favorgen RNA extraction kit, according to manufacturer's instructions. RNA was eluted with $70 \mu$ of RNase free water and stored at $-80^{\circ} \mathrm{C}$ until use in RT-PCR assays.

\section{Primers and RT-PCR}

RT-PCR was performed with My TaqTM OneStep RT-PCR Kit that formulated for first strand CDNA synthesis and subsequent PCR in a single tube. The components of the RT-PCR kit containing 2x My Taq One-Step Mix, forward primer, reverse primer, reverse transcriptase, RiboSaf RNase Inhibitor, and DEPC-H2O.

The primer pairs used in this study are shown in Table 1. 'Primer no. 1' included VP6-F and VP6$R$ for specific amplification of VP6 genes in swine and bovine rotavirus [12]. 'Primer no. 2 ' included JRG7 and JRG8 for specific amplification of full length VP6 genes [13].

Table 1. RT-PCR primers for detection of rotavirus and norovirus from swine and bovine fecal samples

\begin{tabular}{lll}
\hline \multicolumn{1}{c}{ Primer } & \multicolumn{1}{c}{ Sequence (5'-3') } & $\begin{array}{l}\text { Size } \\
\text { (bp) }\end{array}$ \\
\hline 1. VP6-F & 5'-GAC GGV GCR ACT ACA TGG T-3' & 379 \\
VP6-R & 5'-GTC CAA TTC ATN CCT GGT GG-3 & 379 \\
& & \\
2. JRG 7 & 5'-GGC TTT AAA ACG AAG TCT TC-3' & 1356 \\
JRG 8 & 5'-GGT CAC ATC CTC TCA CTA CAT-3' & 1356 \\
\hline
\end{tabular}

Condition of RT-PCR reactions for detection VP6 genes were reverse transcription at $42^{\circ} \mathrm{C}$ or 1 $h$, after an initial denaturation at $95^{\circ} \mathrm{C}$ for $5 \mathrm{~min}$, 35 amplification cycles were performed with denaturation at $94^{\circ} \mathrm{C}$ for $30 \mathrm{~s}$, annealing at $55^{\circ} \mathrm{Cfor} 30 \mathrm{~s}$, and extension reaction at $72^{\circ} \mathrm{C}$ for $45 \mathrm{~s}$, followed by a final extension at $72{ }^{\circ} \mathrm{C}$ for 3 $\min$ [12]. The amplification products were analyzed by $1.5 \%$ agarose gel electrophoresis and visualized by UV light after ethidium bromide staining.

\section{Phylogenetic Analysis}

Nucleotide sequences of the VP6 genes were compared with other strains using BLAST search of the National Center for Biotechnology information (NCBI). Phylogenetic analysis based on the nucleotide alignments was constructed using the neighbor-joining method of Molecular Evolutionary Genetics Analysis (MEGA version 6.0) with a pair-wise distance comparison.

\section{RESULT AND DISCUSSION}

\section{Distribution of Rotavirus in Swine and Bovine in} Taiwan by Age

Distribution of rotavirus positive in group of swine by age was given in Table 2 . The largest proportion of swine rotavirus was noted in piglet $3 / 30(10 \%)$, fattening $0 / 30(0 \%)$, and sow $0 / 30$ (0\%). 1 among 20 samples (5\%) were positive in calf and $0 \%$ in cow. Based on the positive results, the incidence of positive rotavirus was highest among piglets and calf. Probably because pigs did not receive protective levels of maternal antibody, high levels of passive antibody may temporary protect pigs [17].

Table 2.prevalence of rotavirus from swine and bovine on March 2015

\begin{tabular}{|c|c|c|}
\hline Species & Positive Results & Total \\
\hline \multicolumn{3}{|l|}{ Swine } \\
\hline Piglet & $3 / 30$ & $10 \%$ \\
\hline - Fattening & $0 / 30$ & $0 \%$ \\
\hline - Sow & $0 / 30$ & $0 \%$ \\
\hline \multicolumn{3}{|l|}{ Bovine } \\
\hline - Calf & $1 / 20$ & $5 \%$ \\
\hline - Cow & $0 / 60$ & $0 \%$ \\
\hline
\end{tabular}

\section{Sequence and Phylogenetic Analysis}

This study has highlighted the significance of incidence and transmission of swine and bovine rotavirus in Taiwan with human strain. Circulation of animal rotavirus strains confirmed potentially zoonotic $[18,19]$.

Transmission to human is possible not only through direct contact with animals, but also indirectly by contact with contaminated surfaces, food, and water. The risk of zoonotic transmission of rotavirus is higher in rural areas with farms under intensive or extensive management. A part of VP6 gene (1,356 nucleotides in length) was able to be amplified in 2 isolated strains. Nucleotides sequences were compared with other strains in GenBank. 
Taiwan wild strain from swine showing $85.0 \%$ - 91.1\% identity relations with human strains from China (91.1\%), Japan (86.0\%), Vietnam (85.0\%), Japan (85.5\%), and Thailand (85.3\%), showed on Figure 1 . The wild strain of VP6 gene from bovine showing $78.7 \%$ - $85.9 \%$ identity rela- tions with human strains from China and $78.5 \%$ from South Korea, showed on Figure 2.

Phylogenetic tree and homologous identity comparison analysis showed bovine rotavirus had lower transmission risk than swine (Fig. 3 and 4). Some study mentioned that bovine had low incidence and transmission risk for rotavirus [20].
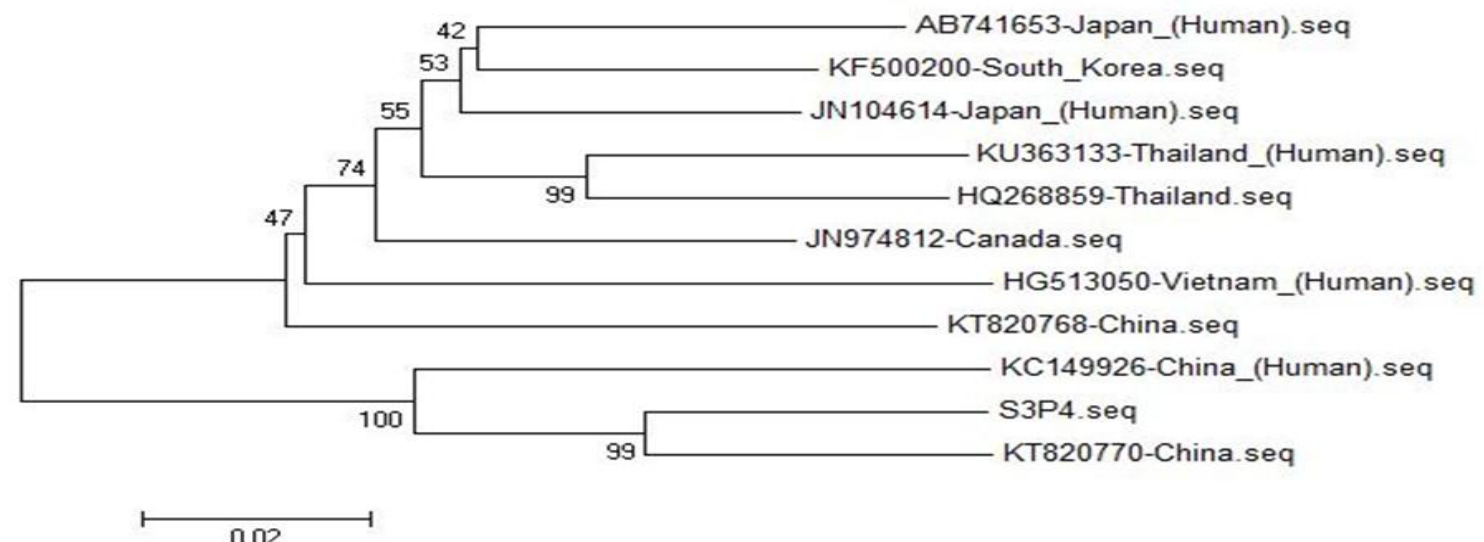

Figure 1. Phylogenetic tree of swine rotavirus based on the VP6 gene ( $1356 \mathrm{bp}$ ) analyzed by MEGA version 6.0 to show the distance of identity relations. Wild strains from Taiwan: south of Taiwan (S3P4). GenBank accession number: KC149926, AB741653, HG513050, JN104614, KU363133, HQ268859, JN974812, KF500200, KT820768, KT820770.

\begin{tabular}{|c|c|c|c|c|c|c|c|c|c|c|c|c|}
\hline \multicolumn{13}{|c|}{ Percent Identity } \\
\hline & 1 & 2 & 3 & 4 & 5 & 6 & 7 & 8 & 9 & 10 & 11 & \\
\hline 1 & & 91.1 & 86.0 & 85.0 & 85.5 & 85.3 & 85.2 & 86.3 & 86.3 & 86.0 & 94.3 & 1 \\
\hline 2 & 9.6 & & 85.3 & 84.9 & 85.8 & 86.6 & 85.6 & 86.4 & 86.5 & 84.7 & 90.9 & 2 \\
\hline 3 & 15.0 & 16.1 & & 90.6 & 93.6 & 91.5 & 91.9 & 92.1 & 93.5 & 90.4 & 85.9 & 3 \\
\hline 4 & 16.3 & 16.5 & 10.3 & & 91.0 & 89.2 & 89.2 & 90.6 & 89.5 & 89.5 & 84.9 & 4 \\
\hline 5 & 15.7 & 15.4 & 6.8 & 9.8 & & 91.9 & 92.4 & 93.3 & 94.1 & 91.4 & 85.2 & 5 \\
\hline 6 & 16.3 & 14.7 & 8.9 & 11.6 & 8.4 & & 94.0 & 92.0 & 92.9 & 89.3 & 85.5 & 6 \\
\hline 7 & 16.4 & 16.0 & 8.4 & 11.6 & 7.8 & 6.4 & & 92.0 & 92.6 & 90.2 & 85.7 & 7 \\
\hline 8 & 15.0 & 15.0 & 8.2 & 9.9 & 6.8 & 8.6 & 8.7 & & 93.0 & 90.5 & 86.3 & 8 \\
\hline 9 & 15.0 & 14.9 & 6.6 & 11.2 & 5.9 & 7.6 & 7.9 & 7.5 & & 89.8 & 86.2 & 9 \\
\hline 10 & 15.1 & 16.9 & 10.6 & 11.6 & 9.4 & 11.5 & 10.4 & 10.1 & 10.9 & & 85.8 & 10 \\
\hline 11 & 5.9 & 9.9 & 15.2 & 16.5 & 16.1 & 16.1 & 15.8 & 15.0 & 15.2 & 15.4 & & 11 \\
\hline & 1 & 2 & 3 & 4 & 5 & 6 & 7 & 8 & 9 & 10 & 11 & \\
\hline
\end{tabular}

S3P4.seq

KC149926-China_(Human).seq AB741653-Japan_(Human).seq HG513050-Vietnam_(Human).seq JN104614-Japan_(Human).seq KU363133-Thailand_(Human).seq HQ268859-Thailand.seq JN974812-Canada.seq KF500200-South_Korea.seq KT820768-China.seq KT820770-China.seq

Figure 2. Homologous identity comparison of swine rotavirus

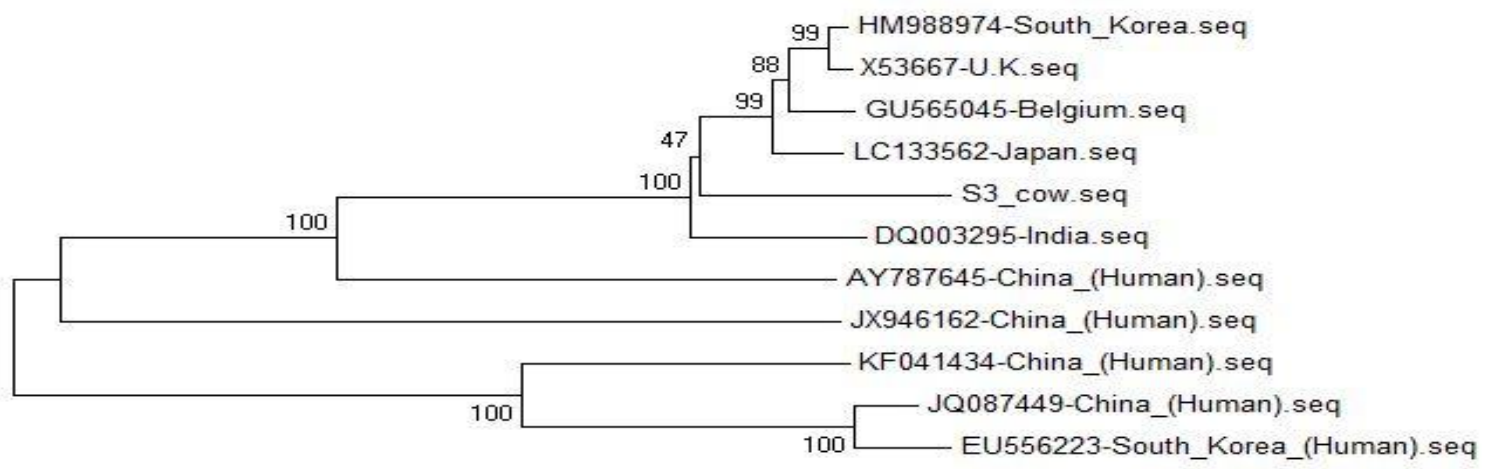
0.02

Figure 3.Phylogenetic tree of bovine rotavirus based on the VP6 gene (1356 bp) analyzed by MEGA version 6.0 to show the distance of identity relations. Wild strains from Taiwan: south of Taiwan (S3_cow). GenBank accession number: AY787645, JQ087449, JX946162, KF041434, EU556223, DQ003295, GU565045, HM988974, LC133562, X53667. 


\begin{tabular}{|c|c|c|c|c|c|c|c|c|c|c|c|c|c|}
\hline \multicolumn{14}{|c|}{ Percent Identity } \\
\hline & 1 & 2 & 3 & 4 & 5 & 6 & 7 & 8 & 9 & 10 & 11 & & \\
\hline 1 & & 85.9 & 78.7 & 80.9 & 79.6 & 78.5 & 94.2 & 94.4 & 94.5 & 94.5 & 94.5 & 1 & S3_cow.seq \\
\hline 2 & 15.9 & & 80.2 & 81.3 & 80.7 & 79.9 & 86.9 & 87.6 & 87.5 & 87.7 & 87.4 & 2 & AY787645-China_(Human).seq \\
\hline 3 & 25.4 & 23.2 & & 80.1 & 90.6 & 97.8 & 79.6 & 79.8 & 79.6 & 79.9 & 79.6 & 3 & JQ087449-China_(Human).seq \\
\hline 4 & 22.3 & 21.7 & 23.4 & & 80.2 & 79.6 & 81.6 & 81.3 & 81.3 & 81.1 & 81.3 & 4 & JX946162-China_(Human).seq \\
\hline 5 & 24.2 & 22.7 & 10.3 & 23.2 & & 90.5 & 80.9 & 80.3 & 80.2 & 80.5 & 80.2 & 5 & KF041434-China_(Human).seq \\
\hline 6 & 25.7 & 23.6 & 2.3 & 24.1 & 10.4 & & 79.2 & 79.4 & 79.3 & 79.5 & 79.3 & 6 & EU556223-South_Korea_(Human).seq \\
\hline 7 & 6.1 & 14.7 & 24.2 & 21.5 & 22.3 & 24.7 & & 95.3 & 95.6 & 95.4 & 95.5 & 7 & DQ003295-India.seq \\
\hline 8 & 5.8 & 13.8 & 23.9 & 21.8 & 23.2 & 24.4 & 5.0 & & 98.2 & 97.8 & 98.3 & 8 & GU565045-Belgium.seq \\
\hline 9 & 5.8 & 14.0 & 24.1 & 21.8 & 23.3 & 24.6 & 4.5 & 1.9 & & 97.9 & 99.4 & 9 & HM988974-South_Korea.seq \\
\hline 10 & 5.6 & 13.6 & 23.7 & 22.0 & 22.9 & 24.2 & 4.8 & 2.2 & 2.0 & & 97.7 & 10 & LC133562-Japan.seq \\
\hline 11 & 5.7 & 14.1 & 24.1 & 21.8 & 23.4 & 24.6 & 4.7 & 1.7 & 0.6 & 2.3 & & 11 & X53667-U.K.seq \\
\hline & 1 & 2 & 3 & 4 & 5 & 6 & 7 & 8 & 9 & 10 & 11 & & \\
\hline
\end{tabular}

These results reflect 2 possible issues: the first is that VP6 rotavirus maybe transferred directly from pig to human or from humans to pig, in which provides zoonotic source for swine rotavirus outbreak. Second, pigs may be co-infected with a human and a swine strain of rotavirus simultaneously [21].

\section{CONCLUSIONS}

Evidence for zoonotic transmission of wild strain rotavirus from Taiwan both in swine and bovine showed in phylogenetic tree and homologous identity comparison analysis. This information will be useful in the rasionalization of genotypes for vaccines to protect Taiwan pigs and cattle. An effective vaccine may potentially reduce zoonotic transmission.

\section{ACKNOWLEDGMENTS}

This work was supported by grants from the project of center for disease control in Taiwan (Taiwan CDC) and microbiology aboratory of department veterinary medicine, National Pingtung University of Science and Technology.

\section{REFERENCES}

[1]. Kim, H.H., J. Matthijnssens, H.J. Kim, H.J. Kwon, J.G. Park, K.Y. Son, E.H. Ryu, D.S. Kim, W.S. Lee, M.I. Kang, D.K. Yang, B.H. Hyun, S.I. Park, S.J. Park, K.O. Cho. 2012. Fulllength genomic analysis of porcine G9P[23] and G9P[7] rotavirus strains isolated from pigs with diarrhea in South Korea. Infect. Genet. Evol. 12. 1427-1435.

[2]. Tate, J.E., A.H. Burton, C. Boschi-Pinto, A.D. Steele, J. Duque, U.D. Parashar. 2012. 2008 estimate of worldwide rotavirus-associated mortality in children younger than 5 years before the introduction of universal rota- virus vaccination programmes: a systematic review and meta-analysis. Lancet Infect. Dis. 12. 136-141.

[3]. Suzuki, T., A. Hasebe, A. Miyazaki, H. Tsunemitsu. 2014. Phylogenetic characterization of VP6 gene (inner capsid) of porcine rotavirus $C$ collected in Japan. Infect. Genet. Evol. 26. 223-227.

[4]. Taiwan CDC. 2015. This year's viral gastroenteritis activity highest in 4 years; As long weekend approaches, public urged to pay attention to personal hygiene to ensure their health and health of others. Available at: https://www.cdc.gov.tw/english/info.

[5]. Kindler, E., E. Trojnar, G. Heckel, P.H. Otto, R. Johne. 2013. Analysis of rotavirus species diversity and evolution including the newly determined full-length genome sequences of rotavirus F and G. Infect. Genet. Evol. 14. 58-67.

[6]. Matthijnssens, J., P.H. Otto, M. Ciarlet, U. Desselberger, M. Van Ranst, R. Johne. 2012. VP6-sequence-based cutoff values as a criterion for rotavirus species demarcation. Arch. Virol. 157. 1177-1182.

[7]. Lachapelle, V., J.S. Sohal, M.C. Lambert, J. Brassard, P. Fravalo, A. Letellier, Y. L'Homme. 2014. Genetic diversity of group A rotavirus in swine in Canada. Arch. Virol. 159. 1771-1779.

[8]. Zhirakovskaia, E.V., R.K. Aksanova, M.G. Gorbunova, A.I. Tikunov, A.M. Kuril'shchikov, S.N. Sokolov, S.V. Netesov, N.V. Tikunova. 2012. Genetic diversity of group A rotavirus isolates found in Western Siberia in 2007-2011. Mol. Genet. Microbiol. Virusol. 33-41.

[9]. Collins, P.J., V. Martella, R.D. Sleator, S. Fanning, H. O'Shea. 2010. Detection and 
characterisation of group A rotavirus in asymptomatic piglets in southern Ireland. Arch. Virol. 155, 1247-1259.

[10]. Thongprachum, A., P. Khamrin, P. Saekhow, C. Pantip, S. Peerakome, H. Ushijima, N. Maneekarn. 2009. Analysis of the VP6 gene of human and porcine group $A$ rotavirus strains with unusual subgroup specificities: Analysis of the VP6 Gene. J. Med. Virol. 81. 183-191.

[11]. Zhu, J., Q. Yang, L. Cao, X. Dou, J. Zhao, W. Zhu, F. Ding, R. Bu, S. Suo, Y. Ren, et al. 2013. Development of porcine rotavirus vp6 protein based ELISA for differentiation of this virus and other viruses. Virol. J. 10(1). 18.

[12]. Iturriza Gomara, M., C. Wong, S. Blome, U. Desselberger, J. Gray. 2002. Molecular characterization of VP6 genes of human rotavirus isolates: correlation of genogroups with subgroups and evidence of independent segregation. J. Virol. 76. 6596-6601.

[13]. Le, L.T., T.V. Nguyen, P.M. Nguyen, N.T. Huong, N.T. Huong, N.T.M. Huong, T.B. Hanh, D.N. Ha, D.D. Anh, J.R. Gentsch, Y. Wang, M.D. Esona, R.I. Glass, A.D. Steele, P.E. Kilgore, N.V. Man, B. Jiang, N.D. Hien. 2009. Development and characterization of candidate rotavirus vaccine strains derived from children with diarrhoea in Vietnam. Vaccine. 27. F130-F138.

[14]. Ghosh, S., N. Urushibara, K. Taniguchi, N. Kobayashi. 2012. Whole genomic analysis reveals the porcine origin of human G9P[19] rotavirus strains Mc323 and Mc345. Infect. Genet. Evol. 12. 471-477.

[15]. Ghosh, S., V. Varghese, S. Samajdar, S.K. Bhattacharya, N. Kobayashi, T.N. Naik. 2006. Molecular characterization of a porcine Group A rotavirus strain with G12 genotype specificity. Arch. Virol. 151. 1329-1344.

[16]. Midgley, S.E., K. Bányai, J. Buesa, N. Halaihel, C.K. Hjulsager, F. Jakab, J. Kaplon, L.E. Larsen, M. Monini, M. Poljšak-Prijatelj, P. Pothier, F.M. Ruggeri, A. Steyer, M. Koopmans, B. Böttiger. 2012. Diversity and zoonotic potential of rotaviruses in swine and cattle across Europe. Vet. Microbiol. 156. 238-245.

[17]. Morrow, W.E.M., 2013. Rotaviral diarrhea in pigs. Swine Health. PIG 04-01-33. 1-6.

[18]. My, P.V.T., M.A. Rabaa, C. Donato, D. Cowley, V.V. Phat, T.T.N. Dung, P.H. Anh, H. Vinh, J.E. Bryant, P. Kellam, G. Thwaites, M.E.J. Woolhouse, C.D. Kirkwood, S. Baker.
2014. Novel porcine-like human G26P[19] rotavirus identified in hospitalized paediatric diarrhoea patients in Ho Chi Minh City, Vietnam. J. Gen. Virol. 95. 2727-2733.

[19]. Martella, V., K. Bányai, J. Matthijnssens, C. Buonavoglia, M. Ciarlet. 2010. Zoonotic aspects of rotaviruses. Vet. Microbiol. 140. 246-255.

[20]. Mauroy, A., A. Scipioni, E. Mathijs, C. Saegerman, J. Mast, J.C. Bridger, D. Ziant, C. Thys, E. Thiry. 2009. Epidemiological study of bovine norovirus infection by RT-PCR and a VLP-based antibody ELISA. Vet. Microbiol. 137. 243-251.

[21]. Mattison, K., A. Shukla, A. Cook, F. Pollari, R. Friendship, D. Kelton, S. Bidawid, J.M. Farber. 2007. Human noroviruses in swine and cattle. Emerg. Infect. Dis. 13. 1184. 